\title{
Evolução histórica dos currículos no setor privado contribuindo para a identidade da Enfermagem (1981-2013) \\ Evolução histórica dos currículos no setor privado contribuindo para a identidade da Enfermagem (1981-2013)
}

\author{
${ }^{1}$ Margarete Bernardo Tavares da Silva margaretetavares@yahoo.com.br \\ 2 Jandilene da Silva Mascarenhas \\ 1 Dinair Leal Hora \\ ${ }^{3}$ Claudia Teresa Vieira de Souza
}

\begin{abstract}
RESUMO:
As mudanças curriculares propostas pelo Ministério da Educação para os cursos da saúde impulsionaram as universidades de enfermagem a um processo de revisão e reformulação de cursos. Pensando nisso, o objetivo deste trabalho é analisar as mudanças curriculares do curso de Enfermagem responsáveis para a determinação do perfil do Enfermeiro egresso de uma Instituição privada no Rio de Janeiro, a Unigranrio. A partir de um estudo histórico-social, que lançou mão de uma análise documental, foram verificados nove currículos entre 1981 e 2013, dentre os quais os dois primeiros se apresentam tímidos no sentido de formação de um profissional envolvido com a transformação social. Após a instituição da LDB/96, a Unigranrio passou a oferecer 32\% da carga horária destinada a disciplinas que contemplam o conceito ampliado de saúde e o "cuidar" do Enfermeiro em todos os campos de atuação, além das discussões transversais nas demais disciplinas, incluindo políticas públicas de saúde, que proporcionam ao aluno a perspectiva da organização do Sistema Único de Saúde (SUS). Concluiu-se que a instituição analisada não seguiu a vertente assistencialista, mas optou pela formação de profissionais para atuar com autonomia, fazendo a diferença nas comunidades, visando um perfil de Enfermeiro com base na subjetividade e criatividade capazes de transformar a realidade na qual a Enfermagem é necessária.
\end{abstract}

Palavras-chave: Ensino. História da enfermagem. Currículo. Prática profissional. Instituições de ensino superior (IES).

\begin{abstract}
:
The changes of the Ministry of Education's propositions to Health formation courses have driven many Nursing Colleges to a review and reformulation process of their education curriculum. Thus, the mainly goal of this article is to analyze the curriculum changes of the Nursing course responsible to define the egress Nurse's profile of a private university from Rio de Janeiro, Unigranrio. Considering a historical-social study based on a documental analysis, nine curriculums, from 1981 to 2013, were examined, showing that the two first were a kind moderate taking into account the formation of professional committed to the social transformation. After the establishment of LDB/96, Unigranrio started to offer 32\% of its academic load to subjects about expanded health conception and the "take care" of the Nurse in all action context. Furthermore, the nursing college presents transversal discussions in all subjects, including health public policies that provide to academics the study of organization of the Unified Health System (hereby SUS). We have concluded that the Education Institution analyzed didn't follow the nursing supporting aspect, but it has been opting to a formation of a professional capable to act with autonomy, making difference inside the social communities, assuring a Nurse's profile based on subjectivity and creativity needed to transform the reality where the Nursing is necessary.
\end{abstract}

Keywords: Education. Nursing history. Curriculum. Professional practice. Higher education institutions.

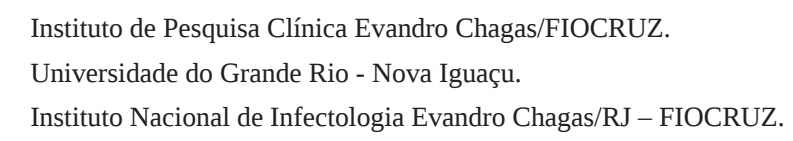




\section{INTRODUÇÃO}

A Enfermagem é uma profissão regulamentada no Brasil pela Lei n. 7498/86 e possui como conceito estruturante o "CUIDAR", que significa desenvolver um cuidado especializado, seguro, eficaz aos pacientes. Para tanto, o Enfermeiro deve sempre pensar, cogitar, julgar, testar, tratar, fazer os preparativos, prevenir-se, criar, zelar e intervir criticamente.

No século XXI, ser Enfermeiro é ter formação generalista, humanista, crítica e reflexiva para exercer as obrigações com base no rigor científico e intelectual, pautado em princípios éticos, atuando com senso de responsabilidade social e comprometido com a atenção integral ao indivíduo. Assim, esse profissional pode intervir sobre os problemas/situações de saúde-doença mais prevalentes no perfil epidemiológico nacional, com ênfase na sua localidade de atuação, identificando as dimensões biopsicossociais e seus determinantes (BRASIL, 2001).

O ensino da Enfermagem moderna no Brasil teve início com a criação da Escola de Enfermeiras do Departamento Nacional de Saúde Pública em 1923; hoje essa instituição se chama Escola de Enfermagem Anna Nery na Universidade Federal do Rio de Janeiro (UFRJ), cuja formação oferecida assenta-se em fundamentos científicos, princípios técnicos, educacionais e éticos, defendendo a ideia de que o cuidado do próximo exige dedicação e preparo, no intuito de minimizar o sofrimento e promover qualidade de vida da população. Em 1931, a instituição foi eleita pelo Ministério da Educação como escola padrão no ensino de Enfermagem, de modo que os demais estabelecimentos de formação de Enfermeiros no país deveriam equiparar-se a ela, no sentido de padronização da estrutura curricular (PADILHA; BORENSTEIN; SANTOS, 2011)

Durante os anos seguintes, o crescimento do número das escolas de Enfermagem não acompanhou o crescimento populacional. Até o final da década de 1940 existiam apenas sete escolas de Enfermagem, sendo seis públicas e uma escola religiosa de administração privada, ocasionando um déficit de profissionais qualificados para o exercício da profissão. Nesse contexto foi promulgada a Lei 775/1949 que regulamentou o ensino de Enfermagem no Brasil, tornando-o obrigatório para todas as faculdades de Medicina e Universidades (LIMA; BAPTISTA, 2000; FERNANDES et al, 2013).

Em 1961, a Organização dos Estados Americanos (OEA) propôs um Plano Decenal de Saúde Pública para as Américas, que tinha como meta principal o combate as enfermidades mais graves no continente. Dentre as suas recomendações estava o investimento na formação de pessoal profissional e auxiliar para a saúde e expansão dos serviços de atenção à Saúde (FERNANDES et al, 2013). No entanto, no Brasil, as instituições públicas de ensino, mesmo com a Reforma Universitária estabelecida pela Lei $N^{\circ}$ 5.540/1968, não conseguiram suprir a demanda dos candidatos ao ensino superior e consequentemente faltava mão de obra qualificada para o mercado de trabalho (LIMA; BAPTISTA, 2000; MELO; MACHADO, 2013).

Após o Plano Decenal de Saúde Pública para as Américas de 1961 e a Reforma Universitária de 1968, além da criação do programa de crédito educativo do Governo Federal em 1976, que viabilizava o financiamento da graduação aos alunos de Instituições de Ensino Superior (IES) privadas, houve um incentivo a criação desses estabelecimentos (MELO; MACHADO, 2013; AMÂNCIO FILHO; VIEIRA, 2006; ARAUJO; GONÇALVES, 2010). Assim sendo, no ano de 1976, inicia-se o primeiro curso de Enfermagem do setor privado no Rio de Janeiro, na Universidade Gama Filho e, no ano de 1981, surge o segundo curso privado de graduação em Enfermagem, na Associação Fluminense de Educação - AFE (LIMA; BAPTISTA, 2000).

Após uma década já havia 106 cursos de Enfermagem no Brasil e com a promulgação da Lei de Diretrizes e Bases da Educação, n. 9.394 de 20 de dezembro de 1996 (LDB/96), e a flexibilização para o sistema de créditos e meio turno no ensino de Enfermagem pela portaria 1.721/94, o número de cursos de graduação em Enfermagem no Brasil cresceu significativamente, mas infelizmente sem um controle rígido de qualidade ou mesmo um estudo sobre a necessidade de oferta desse tipo de formação, proporcionando uma desigualdade regional. No ano 
de 2011 existiam 799 cursos autorizados a funcionar pelo Ministério da Educação (MEC), sendo 127 públicos e 672 privados (FERNANDES et al, 2013; AMÂNCIO FILHO; VIEIRA, 2006; ARAÚJO; GONÇALVES, 2010).

Com o crescimento exponencial de escolas de Enfermagem e a liberdade para organizarem seus currículos, seguindo diretrizes ou parâmetros mínimos nacionais, o modelo da Escola Anna Nery deixou de ser seguido. É importante destacar que na literatura sobre a historiografia dos cursos de Enfermagem no Brasil não tem sido tematizado o surgimento e a contribuição do setor privado na formação do Enfermeiro brasileiro, mesmo essas instituições representando 84\% das Escolas de Enfermagem no país. Por outro lado, a massa de profissionais egressos das instituições privadas não acompanha o nível de capacitação e qualificação dos egressos do setor público, fazendo com que muitos se deparem com o preconceito ao ingressarem no mercado de trabalho devido à sua origem acadêmica, o que não pode ser generalizado para todo o universo da administração privada.

A partir dessa breve contextualização, formulou-se seguinte pergunta: como aconteceu historicamente a organização do curso de Enfermagem na Universidade do Grande Rio (Unigranrio) e a consequente definição do perfil do Enfermeiro ali formado, desde sua origem? Com base neste questionamento, o objetivo deste trabalho é analisar as mudanças curriculares do curso de Enfermagem e o perfil do Enfermeiro egresso. Para isso, foi necessário identificar e analisar esse profissional formado pela Unigranrio com base nos parâmetros e diretrizes curriculares desde sua fundação, além de investigar a presença de conteúdos do conceito ampliado de saúde nos programas das disciplinas que compõem a estrutura curricular da graduação de Enfermagem na Unigranrio.

\section{METODOLOGIA}

Esta pesquisa se trata de um estudo histórico-social, utilizando a análise documental, de acordo com os pressupostos da análise do discurso Escrito por Pêcheux (2012), que nos permite estudar os fenômenos no seu contexto histórico ideológico, o conteúdo e as relações entre o simbólico e o abstrato (SÁ-SILVA, et al, 2009).

A operacionalização da investigação foi realizada no primeiro momento com a análise da estrutura curricular da graduação de Enfermagem na Unigranrio à luz do contexto histórico da época. A pesquisa documental lançou mão dos Projetos Pedagógicos (PP) de todos os currículos implementados desde a criação do curso, bem como os ementários do curso disponíveis, mesmo anteriores às Diretrizes Curriculares Nacionais do Curso de Graduação em Enfermagem estabelecidas pela resolução CNE/CES N 3, de 7 de novembro de 2001 (DCN/2001).

No segundo momento foi realizada a definição, a partir dos documentos analisados anteriormente, do perfil de profissional formado na instituição, seguindo o proposto pelas orientações nacionais para a formação do Enfermeiro brasileiro. Nessa etapa, foram analisados os seguintes documentos: nove grades curriculares do curso de Enfermagem e os ementários que estiveram em vigor no período de 1981 a 2013; dois PP do curso de Enfermagem 1996 e 2005; um relatório de avaliação sobre a escola de Enfermagem de 1999 do Comitê de Avaliação Institucional da Unigranrio; o Plano de Desenvolvimento Institucional (PDI) Unigranrio 2010; dois relatórios de atividades da Pró-Reitoria de Pós-Graduação e Pesquisa 2006 e 2007; cinco relatórios da Pró-Reitoria Comunitária e de Extensão (Proce) 2005-2009.

\section{RESULTADOS}

A Associação Fluminense de Educação, situada na cidade de Duque de Caxias/RJ, foi criada na década de 1970 com o objetivo de aumentar o acesso da população à graduação, contribuindo para melhoria da qualidade de vida. Essa instituição iniciou com dois cursos, Ciências Contábeis e Administração, e com o passar dos anos 
foi ampliando seu leque de ofertas para todas as áreas do conhecimento, contando hoje com um total de 34 bacharelados e 14 graduações tecnológicas (UNIGRANRIO, 2014).

Na década de 1980, iniciaram-se os primeiros cursos da área da saúde: Odontologia, Enfermagem e Farmácia, oferecendo cursos em todas as áreas do conhecimento, como uma das exigências do MEC para credenciar a Associação a tornar-se uma universidade, além de outros pré-requisitos relacionados à pós-graduação, pesquisa e extensão. Em 1994, a AFE passou a ser denominada Unigranrio por reconhecimento na portaria do MEC n. 940 de 16 de junho de 1994.

O curso de Enfermagem e Obstetrícia vinculado à AFE foi autorizado a funcionar pelo Decreto 85.609 de 30 de dezembro de 1980, após parecer do Conselho Federal de Educação nº 1.260/80. No período entre 1981 e 2013, estiveram em vigor no Brasil três orientações nacionais para a formação do Enfermeiro no Brasil, conforme apresentado no quadro 1; no mesmo período, a Unigranrio passou por nove modificações curriculares.

\section{Quadro 1 - Relação dos atos normativos sobre o ensino de Enfermagem no Brasil e o perfil do egresso proposto pela Unigranrio (1972/2013)}

\begin{tabular}{|c|c|c|c|}
\hline \multirow[b]{2}{*}{ Ano } & \multicolumn{2}{|l|}{ Legislação } & \multirow{2}{*}{ Perfil do Enfermeiro Egresso da Unigranrio } \\
\hline & Identificação & Assunto & \\
\hline 1972 & $\begin{array}{l}\text { Resolução } \\
\text { n. } 4 \text { de } \\
25 / 02 / 1972\end{array}$ & $\begin{array}{l}\text { Institui o currículo mínimo } \\
\text { dos cursos de Enfermagem e } \\
\text { Obstetrícia, dividindo-o em } \\
\text { pré-profissional, profissional e } \\
\text { habilitações em uma das grandes } \\
\text { áreas: Enfermagem Obstétrica, } \\
\text { Enfermagem em Saúde Pública, } \\
\text { Enfermagem Médico-Cirúrgica. }\end{array}$ & $\begin{array}{l}\text { Enfermeiro com uma visão da atenção primária } \\
\text { e preparado para atuar na atenção a saúde em } \\
\text { ambiente hospitalar. } \\
\text { Enfatizava a necessidade de o Enfermeiro } \\
\text { dominar cada vez mais as técnicas avançadas em } \\
\text { saúde, em razão da evolução científica }{ }^{1} \text {. }\end{array}$ \\
\hline 1994 & $\begin{array}{l}\text { Portaria } \\
\text { n. } 1.721 \text { de } \\
15 / 12 / 1994 .\end{array}$ & $\begin{array}{l}\text { Dispõe sobre a formação do } \\
\text { Enfermeiro, que será feita em } \\
\text { curso de graduação, extingue as } \\
\text { habilitações e incorpora as Ciências } \\
\text { Sociais. } \\
\text { Considerava perfil sanitário e } \\
\text { epidemiológico da população, } \\
\text { a organização dos serviços de } \\
\text { saúde, o processo de trabalho em } \\
\text { Enfermagem e a articulação entre o } \\
\text { ensino e os serviços. }\end{array}$ & $\begin{array}{l}\text { Profissional generalista, compromissado com a } \\
\text { sociedade. Valorizando um processo de ensino } \\
\text { aprendizagem critico-reflexivo }{ }^{2} \text {. }\end{array}$ \\
\hline 2001 & $\begin{array}{l}\text { Diretrizes } \\
\text { Curriculares } \\
\text { Nacionais } \\
\text { do Curso de } \\
\text { Graduação em } \\
\text { Enfermagem } \\
\mathrm{n}^{\circ} 03 / 2001\end{array}$ & $\begin{array}{l}\text { Extingue o currículo mínimo e } \\
\text { delimita o perfil do Enfermeiro } \\
\text { brasileiro. }\end{array}$ & $\begin{array}{l}\text { O egresso será capaz de desenvolver o cuidar } \\
\text { como algo superior ao ato técnico, percebendo } \\
\text { a sua capacidade de atuar como um agente } \\
\text { transformador da realidade, reconhecendo } \\
\text { o perfil epidemiológico como um agente } \\
\text { promotor da saúde integral do indivíduo, família } \\
\text { e comunidade. É capaz de colaborar com as } \\
\text { modificações necessárias através de ações } \\
\text { baseadas nos pressupostos do saber técnico- } \\
\text { científico e da consciência de seu papel social }{ }^{3} \text {. }\end{array}$ \\
\hline
\end{tabular}

1 - Unigranrio. Estrutura Curricular de Graduação em Enfermagem do Departamento de Enfermagem, Duque de Caxias, 1981 e 1989.

2 - Unigranrio. Estrutura Curricular do Curso de Graduação em Enfermagem do Departamento de Enfermagem. Duque de Caxias: 1996. 3 - Unigranrio. Projeto Pedagógico do Curso de Enfermagem. Escola de Ciências da Saúde. Duque de Caxias: 2004.

Fonte: ?

Após análise da composição disciplinar de cada currículo pela leitura das ementas de cada disciplina, elas foram agrupadas em três eixos: 1- Assistência à Saúde coletiva e pesquisa - inclui conteúdos voltados para aten- 
ção básica, conceito ampliado de saúde, legislação, história e metodologia da pesquisa (tabela 1); 2- Assistência à Saúde pelos ciclos de vida na média e alta complexidade (tabela 2); 3- Ciências básicas na Saúde.

Tabela 1 - Distribuição dos créditos por disciplinas com foco na Assistência à Saúde Coletiva/Pesquisa, pelos currículos do curso de Enfermagem da Unigranrio Duque de Caxias/RJ, no período de 1981 a 2013

\begin{tabular}{|c|c|c|c|c|c|c|c|c|c|}
\hline DISCIPLINAS & 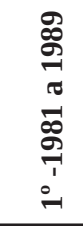 & 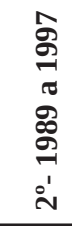 & $\begin{array}{l}\infty \\
\stackrel{2}{\sigma} \\
\pi \\
\hat{\sigma} \\
\stackrel{2}{\sigma} \\
\text { ì }\end{array}$ & 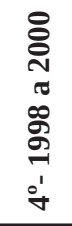 & 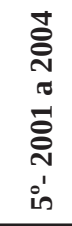 & 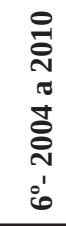 & 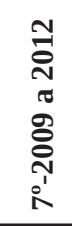 & 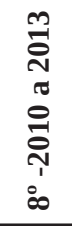 & 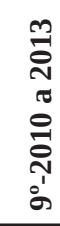 \\
\hline Antropologia Filosófica & & & 2 & 2 & 2 & & & & \\
\hline Atenção a Saúde da Coletividade & & & & & & 3 & 3 & 2 & 2 \\
\hline Bioestatística / Estatísticas vitais & 2 & 2 & 3 & 3 & 3 & & & & \\
\hline Contexto Sócio Antropológico & & & & & & 3 & 2 & 3 & 3 \\
\hline Educação em Saúde & & & & & & 3 & 3 & 2 & 2 \\
\hline Enfermagem em Doenças Transmissíveis & 5 & 3 & 3 & 3 & 3 & & & & \\
\hline Epidemiologia e Saúde & 2 & 2 & 3 & 3 & 3 & 3 & 2 & 2 & 2 \\
\hline Estágio em Enfermagem em Doenças Transmissíveis & 4 & 4 & 5 & 5 & 5 & & & & \\
\hline Estágio em Saúde Coletiva 1 & & & 3 & 2 & 2 & & & & \\
\hline Estágio em Saúde Coletiva 2 e 3 & & & 10 & 10 & 5 & & & & \\
\hline Metodologia da Pesquisa em Enfermagem 2 a 3 & & & 4 & 2 & 2 & & & & \\
\hline Metodologia da Pesquisa em Enfermagem 1 & & 2 & 2 & 2 & 2 & & 2 & & \\
\hline Monografia/Trabalho de Conclusão de Curso 1 e 2 & & & 4 & 4 & 4 & 3 & 3 & 5 & 5 \\
\hline Organização do Sistema de Saúde & & & & & & 3 & 3 & 2 & 2 \\
\hline Práticas Alternativas em Saúde & & 3 & 3 & 3 & & & & & \\
\hline Prociepe ${ }^{1}$ Prática Curricular em Saúde 1 a 3 & & & & & & & & 6 & 6 \\
\hline Prociepe $^{1} 4$ e 5 / Pcap ${ }^{2} 1$ e 2 & & & & & & & & 12 & 13 \\
\hline Programa Integralizador 1 a 3 & & & & & & & 9 & & \\
\hline Saneamento & 3 & 2 & & & & & & & \\
\hline Saúde Ambiental & & & 3 & 3 & 3 & & & & \\
\hline Saúde Coletiva 1 a 3 & & & 12 & 12 & 8 & & & & \\
\hline Saúde da Comunidade/ Sociedade & 2 & 2 & & & & 6 & 2 & & \\
\hline Seminário Família e Comunidade 1 a 3 & & & & & & 4 & 6 & & \\
\hline Seniorato & & & 6 & & & & & & \\
\hline Sociologia Geral & 2 & 2 & 2 & 2 & 2 & & & & \\
\hline Trabalho de Conclusão de Curso 3 & & & & & & & & 2 & 2 \\
\hline TOTAL DE CRÉDITOS & 20 & 22 & 65 & 56 & 44 & 28 & 35 & 36 & 37 \\
\hline
\end{tabular}

${ }^{1}$ Prociepe-Programa Curricular de Integração: Ensino Pesquisa e Extensão; ${ }^{2}$ Pcap- Prática Curricular na Atenção Primária. 
Tabela 2 - Distribuição dos créditos das disciplinas com foco na Assistência à Saúde em nível de Média e Alta Complexidade, pelos currículos do curso de Enfermagem da Unigranrio, Duque de Caxias/RJ, no período de 1981 a 2013

\begin{tabular}{|c|c|c|c|c|c|c|c|c|c|}
\hline DISCIPLINAS & 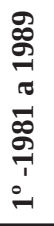 & 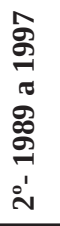 & 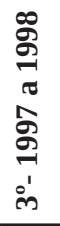 & 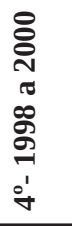 & 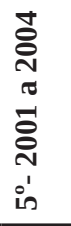 & 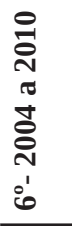 & 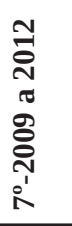 & 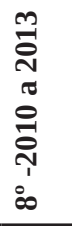 & 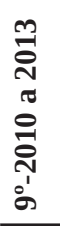 \\
\hline Ações de Enfermagem em Oncologia & & & & & & & & 3 & 3 \\
\hline Contexto Histórico-Legal do Trabalho em Enf. & 2 & 2 & 4 & 4 & 4 & 3 & 2 & 2 & 2 \\
\hline Didática aplicada a Enfermagem & 3 & 3 & 3 & 3 & 3 & & & & \\
\hline Enfermagem Centro-Cirúrgico - Teoria e Estágio Supervisionado & 7 & & & & & & & & \\
\hline Enfermagem Fundamental - Teoria & 7 & 4 & 4 & 4 & 4 & & & & \\
\hline Enfermagem Ginecologia/Obstetrícia - Teoria e Estágio Supervisionado & 8 & 9 & 9 & 9 & & & & & \\
\hline Enfermagem Materno-Infantil- Teoria e Estágio Supervisionado & 7 & 7 & & & & & & & \\
\hline Enfermagem Médica - Teoria e Estágio Supervisionado & & 8 & 8 & 9 & 9 & & & & \\
\hline Enf. Médico-Cirúrgica - Teoria e Estágio Supervisionado & 9 & 9 & 9 & 9 & 9 & & & & \\
\hline $\begin{array}{l}\text { Enfermagem na Emergência Hospitalar - Teoria e Estágio } \\
\text { Supervisionado }\end{array}$ & & & & & & & & 3 & 3 \\
\hline Enfermagem Pediátrica e Neonatal - Teoria e Estágio Supervisionado & 6 & 8 & 9 & 9 & & & & & \\
\hline Enfermagem Psiquiátrica - Teoria e Estágio Supervisionado & 6 & 6 & 8 & 8 & 8 & & & & \\
\hline Estágio em Enfermagem Fundamental & & 5 & 5 & 5 & 5 & & & & \\
\hline Estágio em Gerenciamento do Serviço de Enfermagem & 3 & 3 & 10 & 2 & 2 & & & & \\
\hline Estágio Supervisionado Geral ou Integralizador 1 e 2 & & & & 25 & 25 & 32 & 32 & 44 & 44 \\
\hline Gerenciamento/Administração do Serviço de Enfermagem 1-2 & 3 & 2 & 5 & 4 & 4 & 5 & 5 & 6 & 6 \\
\hline Interpretação: Exames Laboratoriais/Métodos Auxiliares de diagnóstico & & & & & & 3 & 3 & 3 & 3 \\
\hline Processos Patológicos Gerais & 4 & 4 & 4 & 4 & 4 & 4 & 4 & 4 & 4 \\
\hline Prociepe $^{1} 6$ a 8/ PCMA $^{\dagger} 6$ a 8 & & & & & & & & 23 & 25 \\
\hline Sistematização da Assistência de Enfermagem ao Paciente Crítico & & & & & & 6 & 6 & 3 & 3 \\
\hline Saúde da Mulher - teoria e prática & & & & & 12 & 13 & 13 & 8 & 8 \\
\hline Saúde da Criança - teoria e prática & & & & & 12 & 13 & 13 & 9 & 9 \\
\hline Saúde do Adulto/Idoso 1 a 4 & & & & & & 27 & 27 & 12 & 12 \\
\hline Saúde Mental & & & 3 & 3 & 3 & 3 & & 6 & 6 \\
\hline Semiologia e Semiotécnica/Processo do Cuidar & & & 3 & 3 & 3 & 12 & 12 & 12 & 13 \\
\hline Urgências E Emergências Pré-Hospitalar & & & & & 3 & 3 & 3 & 3 & 3 \\
\hline TOTAL DE CRÉDITOS: & 65 & 70 & 84 & 101 & 110 & 124 & 120 & 141 & 144 \\
\hline
\end{tabular}

${ }^{1}$ Programa Curricular de Integração: Ensino Pesquisa e Extensão; †Prática Curricular na Média e Alta Complexidade

Fonte: Autores.

Segundo a pró-reitora de graduação, os docentes da Unigranrio, em reuniões colegiadas e grupos de discussão, se propuseram a construção de um PP que viesse romper com o modelo predominantemente assistencialista e hospitalocêntrico até então em vigor. A ruptura exigiu dos docentes também modificações no modo de entender o processo ensino-aprendizagem. 


\section{DISCUSSÃO}

Na época de criação do curso de Enfermagem da AFE, estava em vigor no Brasil a Resolução do MEC n. 4 de 25 de fevereiro de 1972, que instituía o currículo mínimo para os cursos de graduação em Enfermagem Obstétrica. Esse currículo tinha um foco assistencial a nível hospitalar e dividia a graduação em Enfermagem em tronco pré-profissional e profissional. Assim, indicamos o foco assistencial com base na distribuição das disciplinas obrigatórias definidas pelo MEC, dentre as quais 95\% eram para a formação de um Enfermeiro que atuasse na média e alta-complexidade, em detrimento dos conteúdos de Saúde Pública que ficavam restritos às habilitações eletivas após a conclusão dos cursos regulares (STUTZ, 2010; SILVA et al, 2010).

Como vimos nas tabelas 1 e 2, nos dois primeiros currículos analisados, eram mínimos os créditos destinados às disciplinas do campo da Saúde Pública, nas quais o foco era uma assistência em nível de prevenção e promoção da saúde. A formação era, sim, pautada na assistência hospitalar, preparando Enfermeiros para aquisição de habilidades técnicas necessárias ao mercado de trabalho em franco crescimento com a expansão dos planos de saúde e, consequentemente, a ampliação dos leitos hospitalares em todo o Brasil (FERNANDES et al, 2013).

A primeira turma de Enfermagem na Unigranrio colou grau em 31 de março de 1984, com vinte formandas. O currículo que as formou possuía uma grade comum que totalizava 2.700 horas/aula, equivalentes a 138 créditos divididos em tronco básico e profissionalizante, além da habilitação que poderia ser em Saúde Pública (mais 760 horas/aula) ou Licenciatura (mais 860 horas/aula). Dos 138 créditos, 57 pertenciam ao ciclo básico e 81 ao profissionalizante e destes somente 20 de Saúde Coletiva. Corroboram esse fato Amâncio Filho e Vieira (2006), lembrando que o foco das IES, nessa época, era formar profissionais para "abastecer” o mercado de trabalho, o que distorcia um dos objetivos da AFE de proporcionar as comunidades melhoria da qualidade de vida e oferecer atividades de extensão, aproximando os alunos a comunidade (MELO; MACHADO, 2013; ARAÚJO et al, 2006; NEPOMUCENO et al, 2013; BISCARDE et al, 2014; PAULA, 2013).

A organização do currículo, pautada na atenção à saúde de média e alta complexidade (tabela 2), contribuiu para a disponibilização ao mercado Brasileiro, já que nas décadas de 1970 e 1980 houve um crescimento das redes hospitalares e não havia profissionais para atuarem nestas instituições (FERNANDES et al, 2013; MELO, MACHADO, 2013; AMÂNCIO FILHO; VIEIRA, 2006; ARAÚJO et al, 2010).

De acordo com a resolução 4/1972, o currículo mínimo preestabelecido tinha de ser seguido pela IES, ou seja, a formação era voltada para atenção à saúde de média/alta complexidade, pois o mercado de trabalho à época necessitava de profissionais habilitados para os hospitais que estavam sendo erguidos (ARAÚJO et al, 2010). No entanto, desde sua criação, o curso de Enfermagem da Unigranrio buscou aproximar seu aluno da realidade profissional através de projetos de extensão comunitária; ao todo foram 28 projetos registrados, como o Espaço (Con)Viver e o Projeto Integrado - Pró-saúde (Jardim Gramacho, Duque de Caxias).

Assim, o desafio naquela época foi trazer à discussão dos alunos o significado social e humano do trabalho por meio das disciplinas e atividades de extensão oferecidas (PAULA, 2013). A presença contínua nas discussões do conceito ampliado de saúde e o "cuidar" do Enfermeiro em todos os campos de atuação perpassavam todos os currículos do curso de Enfermagem desde sua criação, mesmo que de forma limitada nos primeiros anos. O percentual de créditos disponibilizados em disciplinas da atenção primária estava em torno de 12\%; dos 138 créditos do curso, 120 eram preenchidos com disciplinas focadas na assistência hospitalar (Tabelas 1 e 2). Como exemplo, destaca-se a disciplina de Epidemiologia que esteve presente em todos os nove currículos, pois nela são discutidos temas como a história do conceito de Saúde, o processo saúde-doença, a tríade epidemiológica, além de trazer outros conhecimentos que subsidiam o desenvolvimento de outras disciplinas (Tabela 1).

Com as mudanças ocorridas em 1994 introduzidas pela Portaria 1.721/94 (BRASIL, 1994), que incorpora aos currículos de Enfermagem matérias e disciplinas das ciências humanas, inicia-se um processo de revisão cur- 
ricular nas IES de todo o Brasil. Com a LDB/96 (BRASIL, 1996) e a reorganização do ensino brasileiro, as IES veem-se diante do desafio de deixar os currículos mínimos preestabelecidos pelo MEC para construir o próprio Projeto Pedagógico do Curso (PPC) de acordo com a política pedagógica institucional.

Dessa forma, a Unigranrio iniciou a nova organização curricular no segundo semestre de 1997 com 54 disciplinas obrigatórias, totalizando 3.920 horas/aula. No primeiro semestre de 1998, a nova disposição entra em vigor e segue até o segundo semestre de 2000, contanto com 41 disciplinas obrigatórias, totalizando 4.080 horas/ aula; em 2001, outra grade entra em atividade com 39 disciplinas e carga horária de 3.960 horas/aula. Em ambos os currículos, se destaca o crescente percentual de disciplinas com o foco na atenção básica à saúde e ao conceito ampliado de saúde (Tabela 1). Nessa última mudança foram acrescentadas ao currículo do curso de Enfermagem disciplinas como: Antropologia Filosófica, Psicologia, Saúde Mental, Seniorato, disciplinas que estimulam o raciocínio crítico, reflexivo e discutem a saúde como direito do cidadão (Tabela 1 e 2).

Vale salientar que as três mudanças na proposta curricular da Unigranrio entre 1997 e 2001 estavam dentro dos parâmetros definidos no Projeto Político de Curso (PPC) construído e apresentado ao MEC, após a Portaria 1721/1994 (BRASIL, 1994). As alterações foram necessárias porque não foram apenas conceituais, mas também filosóficas e estruturais. Assim, a nova proposta curricular acrescenta disciplinas que levam o aluno no terceiro período para comunidades a fim de identificar seus problemas e propor mecanismos de intervenção através do estágio em Saúde Coletiva. Os discentes passam a ter quatro semestres de estágio com foco na atenção primária e quatro semestres de disciplina teórica para discutir a Saúde Coletiva. Dessa forma, o Enfermeiro egresso da Unigranrio passa a ser um profissional generalista, pois não existem mais habilitações; é um profissional preparado para o mercado de trabalho atual comprometido com a sociedade onde está inserido (UNIGRANRIO, 2004).

Com as DCN 03/2001 (BRASIL, 2001), uma comissão de avaliação e elaboração do novo PPC é organizada. Após o trabalho de diálogos com alunos, egressos e Enfermeiros das unidades de estágio, é definido o perfil do egresso de Enfermagem e com isso uma nova organização curricular entra em atividade no primeiro semestre de 2005, com 41 disciplinas, totalizando 3.850 horas/aula, concretizadas em oito semestres no mínimo. Cabe destacar que foi nesse currículo que encontramos o maior percentual de disciplinas com foco na atenção primária à saúde da população 31\% (Tabela 1).

O Enfermeiro egresso da Unigranrio formado pelo currículo de 2005 é um profissional com habilidades e competências que o possibilitam atuar em todas as áreas da atenção à saúde, desenvolvendo a Sistematização da Assistência de Enfermagem, a partir de uma avaliação crítica e reflexiva da realidade epidemiológica da comunidade onde possa estar inserido, de forma a propor ações de intervenção e promoção a saúde integral ao indivíduo, sua família e comunidade. Outrossim, apresenta capacidade de desenvolver na esfera pessoal habilidades e competências que o auxiliem no enfrentamento das diversas situações que vivenciará, formando não apenas um profissional, mas também um cidadão (UNIGRANRIO, 2004; SILVA, 2010; APPLE, 2006).

Na busca de melhorias na formação não só do Enfermeiro, mas dos profissionais da saúde, o Governo Brasileiro propõe uma ação conjunta entre o Ministério da Educação e o Ministério da Saúde que se refere a um incentivo financeiro para os cursos de Enfermagem, Medicina e Odontologia para a reorientação da formação dos profissionais, numa perspectiva de abordagem integral do indivíduo, com base no processo saúde-doença "Programa Nacional de Reorientação da Formação Profissional em Saúde”, o Pró-Saúde (BRASIL, 2007). Além disso, a partir desse incentivo, a Unigranrio faz adequações no currículo, com a finalidade de atender à demanda de aproximação do aluno aos serviços de saúde, preparando-os para responder às necessidades de sua comunidade e articulando conhecimentos para a resolução dos problemas dentro dos serviços do SUS.

O currículo passou a ser estruturado com questões transversais que perpassam todas as disciplinas inter-relacionadas de forma espiralada, divididas em três grandes eixos: 1) O cuidar na dimensão da Saúde e Sociedade - do $1^{\circ}$ ao $3^{\circ}$ período, com o foco de contextualizar a atenção a saúde, trabalhando o processo saúde-doença 
a partir da sociedade em que o sujeito está inserido até o nível individual. 2) O cuidar na dimensão do processo saúde-doença nos ciclos de vida - do $4^{\circ}$ ao $6^{\circ}$ período, com foco no desenvolvimento de habilidades e competências para que o enfermeiro possa desenvolver o cuidado de enfermagem sistematizado à população em todas as necessidades de saúde, nas diferentes fases da vida; 3) Imersão na prática do cuidar em Enfermagem - do $7^{\circ}$ ao $8^{\circ}$ período, para o desenvolvimento de atividades práticas da sistematização da assistência de Enfermagem (UNIGRANRIO, 2004).

Ao examinar todos os planos de ensino das 41 disciplinas desse currículo, verificou-se os pontos fortes e as suas limitações de acordo com as DCNs 03/2001. Cabe a pontar que dentre as 33 competências e habilidades apresentadas nas Diretrizes Curriculares Nacionais para o curso de Enfermagem, o currículo da Unigranrio não contempla a gestão dos projetos de saúde em estruturas públicas e privadas, configurando uma fragilidade nessa área.

\section{CONSIDERAÇÕES FINAIS}

A história da organização do curso de Enfermagem na Unigranrio e o perfil do Enfermeiro formado por esta Instituição foram descritos e contextualizados no decorrer deste texto. Na análise, a organização disciplinar dos currículos evidenciou a transversalidade de um eixo de cuidado à saúde em todas as dimensões do indivíduo e da sociedade onde ele está inserido.

Para além da visão ampliada de saúde e a atuação com a visão de transformação social, o egresso do curso de Enfermagem da Unigranrio apresentou uma base sólida de políticas públicas de saúde que proporcionou a perspectiva da Organização do Sistema Único de Saúde (SUS), favorecendo o compromisso com a defesa de um sistema coerente com a proposta da integralidade de atenção, englobando ações de promoção, proteção e recuperação da saúde.

Acreditamos que esta investigação possa subsidiar futuros estudos. Mesmo com as delimitações legais, o curso de Enfermagem da Unigranrio procurou fornecer aos estudantes uma formação diferenciada, favorecendo ao egresso não apenas a capacidade de inserção no mercado de trabalho, mas colaborando para sua perspectiva crítica e social. 


\section{REFERÊNCIAS}

AMÂNCIO FILHO A., VIEIRA A. L. S. Dinâmica das graduações em saúde no Brasil: subsídios para uma política de recursos humanos. Brasília: Ministério da Saúde/Fundação Oswaldo Cruz, 2006.

APPLE, M. W. Ideologia e Currículo. 3. ed. Tradução de Vinicius Figueira. Porto Alegre: Artmed, 2006.

ARAÚJO, F. F.; GONÇALVES, F. M.; ALMEIDA A. C. V; SIQUEIRA, A. S. A Enfermagem e a democratização do acesso à educação superior brasileira: desafios a serem enfrentados. Revista Rede de Cuidados em Saúde, Rio de Janeiro, v. 4, n. 1, p. 1-17, 2010. Disponível em: <http://publicacoes.unigranrio.br/index.php/rcs/article/ view/1042>. Acesso em: 15 nov. 2015.

BISCARDE, D. G. S.; PEREIRA-SANTOS, M.; SILVA, L. B. Formação em saúde, extensão universitária e Sistema Único de Saúde (SUS): conexões necessárias entre conhecimento e intervenção centradas na realidade e repercussões no processo formativo. Interface, Botucatu v. 18, n. 48, p. 177-186, 2014. Disponível em: <http://www.scielo.br/ scielo.php?script=sci_arttext\&pid=S1414-32832014000100177\&lng=en>. Acesso em: 15 mar. 2016.

BRASIL. Lei 9.493/1996 de 20 de dezembro de 1996. Emenda Constitucional n. 11 de 1996. Emenda Constitucional n. 14 de 1996. Lei 9.424 de 24 de dezembro de 1996. Senado Federal, Secretaria Especial de Editoração e Publicações, Subsecretaria de Edições Técnicas. Estabelece as leis de diretrizes e bases da educação nacional. Leis de Diretrizes e Bases da Educação Nacional. Brasília: DF, 1996. Disponível em: <https:// www2.senado.leg.br/bdsf/bitstream/handle/id/70320/65.pdf?sequence=3>. Acesso em: 10 jan. 2016.

BRASIL. Ministério da Saúde. Ministério da Educação. Pró-Saúde - Programa Nacional de Reorientação da Formação Profissional em Saúde. Objetivos, Implementação e Desenvolvimento Potencial. Brasília, 2007. Disponível em: <http://www.prosaude.org/publicacoes/pro_saude1.pdf>. Acesso em: 18 jan. 2016.

BRASIL. Portaria n. 1721 de 15 de dezembro de 1994. Dispõe sobre a formação do Enfermeiro, que será feita em curso de graduação e cumprirá os mínimos de conteúdo e de duração fixados pela presente portaria. Diário Oficial da União, 16 dez. 1994. Disponível em: <http://pesquisa.in.gov.br/imprensa/jsp/visualiza/index. jsp?data=16/12/1994\&jornal=1\&pagina=69\&totalArquivos=152>. Acesso em: 18 jan 2016.

BRASIL. Resolução do CNE/CSE n. 03 de 07 de novembro de 2001. Dispõe sobre as Diretrizes Curriculares Nacionais para Enfermagem. Diário Oficial da União, Brasília, 3 abr. 2011. Disponível em: http:// portal.mec.gov.br/conselho-nacional-de-educacao/atos-normativos--sumulas-pareceres-e-resolucoes/323secretarias-112877938/orgaos-vinculados-82187207/13193-resolucao-ces-2001>. Acesso em: 10 jan. 2016.

FERNANDES, J. D.; TEIXEIRA, G. A. S.; SILVA, M. G.; FLORÊNCIO R. M.; SILVA, R. M. O.; ROSA, D. O. S. Expansion of higher education in Brazil: increase in the number of Undergraduate Nursing courses. Expansion of higher education in Brazil: increase in the number of Undergraduate Nursing courses. Rev. LatinoAm. Enfermagem, Ribeirão Preto, v. 21, n. 3, p. 670-678. mai./jun. 2013. Disponível em: <http://www.scielo. br/scielo.php?script=sci_arttext\&pid=S0104-11692013000300670\&lng=en>. Acesso em: 13 mai. 2016.

LIMA, T. G. F.; BAPTIST, A. S. S. Circunstâncias de criação das escolas de Enfermagem do Estado do Rio de Janeiro. Rev. Esc. Anna Nery, Rio de Janeiro, v. 4, n. 2, p. 197-208, ago. 2000. Disponível em: <http:// revistaenfermagem.eean.edu.br/detalhe_artigo.asp?id=1181>. Acesso em: 20 jan. 2016.

MELO, C. S.; MACHADO, M. C. G. Apontamentos de Álvaro Vieira pinto à reforma universitária no Brasil na década de 1960. Revista HISTEDBR On-line, Campinas, v. 13, n. 53, p. 263-279, out. 2013. Disponível em: http://ojs.fe.unicamp.br/ged/histedbr/article/view/5923/4894>. Acesso em: 20 jan. 2016.

NEPOMUCENO, C.C., JERONYMO A.C.O., FERNANDES B.M., FREITAS S.C. Cuidar por meio da educação: a extensão universitária e a promoção da saúde de adolescentes e jovens. Em Extensão, Uberlândia, 
v. 12, n. 1, p. 150-158, jan./jun. 2013. Disponível em: <http://www.seer.ufu.br/index.php/revextensao/article/ view/20851>. Acesso em: 15 mar. 2016.

PADILHA, M. I. C. S.; BORENSTEIN, M. S.; SANTOS I. Enfermagem, história de uma profissão. São Caetano do Sul: Difusão editora, 2011.

PAULA, J. A. A extensão universitária: história, conceito e propostas. Interfaces - Revista de Extensão, Belo Horizonte, v. 1, n. 1, p. 5-23, jul./nov. 2013. Disponível em: <https://www.ufmg.br/proex/revistainterfaces/ index.php/IREXT/article/view/5>. Acesso em: 15 mar. 2016.

PÊCHEUX, M. O discurso: estrutura ou acontecimento. 6. ed. Tradução de Eni P. Orlandi. Campinas: Pontes Editores, 2012.

SÁ-SILVA, J. R.; ALMEIDA, C. D.; GUINDANI, J. F. Pesquisa documental: pistas teóricas e metodológicas. Revista Brasileira de História \& Ciências Sociais, São Leopoldo, v. 1, n. 1, p. 1-15, jul. 2009. Disponível em: $<$ https://www.rbhcs.com/rbhcs/article/view/6>. Acesso em: 14 jan. 2016.

SILVA, M. G.; FERNANDES, J. D.; TEIXEIRA, G. A. S.; SILVA, R. M. O. Processo de formação da(o) Enfermeira(o) na contemporaneidade: desafios e perspectivas. Texto Contexto Enfermagem, Florianópolis, v. 19, n.1, p. 176-184, jan./mar. 2010. Disponível em: <http://www.scielo.br/pdf/tce/v19n1/v19n1a21.pdf >. Acesso em: 21 jan. 2016.

SILVA, T. T. Documentos de identidade: uma introdução as teorias do currículo. 3 ed. Belo Horizonte: Autêntica, 2010.

STUTZ, B. L. As primeiras Escolas de Enfermagem e o desenvolvimento desta profissão no Brasil. Cadernos de História da Educação, Uberlândia, v. 9, n. 2, p. 347-362, jul./dez. 2010. Disponível em: <http://www.seer. ufu.br/index.php/che/article/view/11450>. Acesso em: 20 jan. 2016.

UnIVERSIDADE DO GRANDE RIO (UNIGRANRIO). Projeto Pedagógico do Curso de Enfermagem. Duque de Caxias: Escola de Ciências da Saúde, Curso de Enfermagem, 2004. 